\title{
فهرس المحتويات
}

\begin{tabular}{|c|c|c|}
\hline (الصفةة & عiوان البحث & 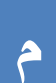 \\
\hline 1 & 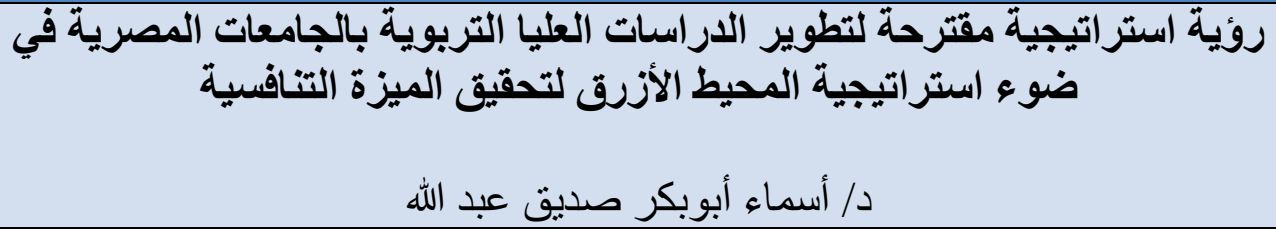 & 1 \\
\hline 77 & 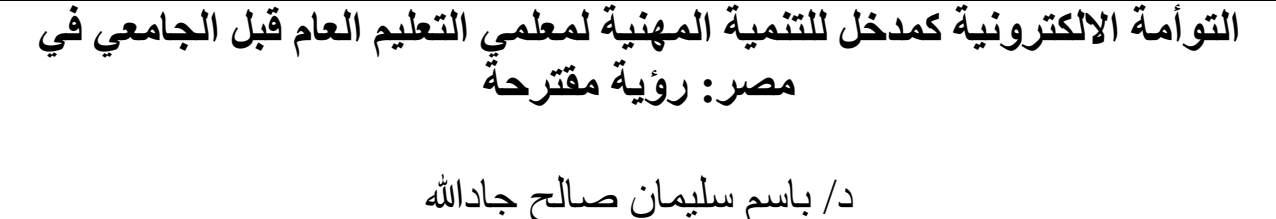 & $r$ \\
\hline$|r|$ & 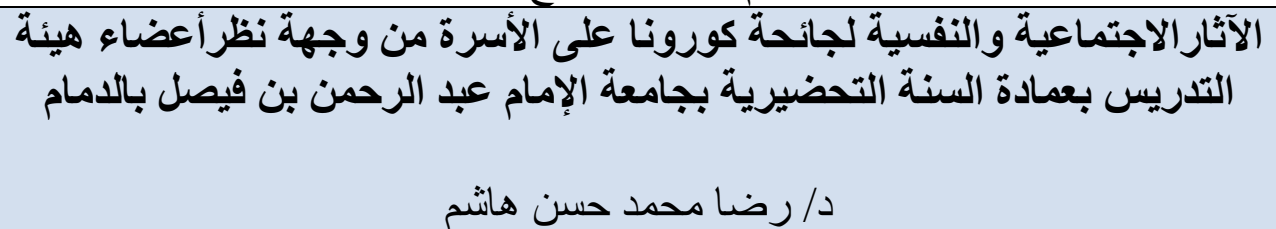 & $r$ \\
\hline 171 & الرفاهية الأكاديمية وعلاقتها بسمة ما وراء المزاج لدى طالبات الجامعة & $\varepsilon$ \\
\hline $19 \leqslant$ & 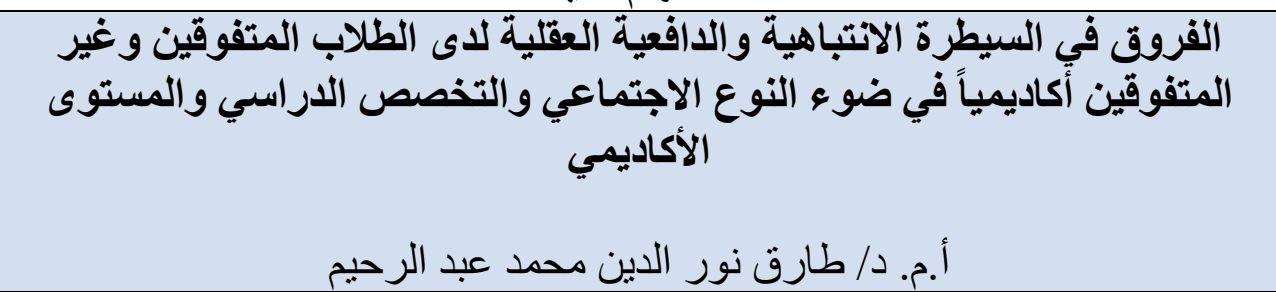 & 0 \\
\hline ६ & رشاقة التعلم في علاقتها بعوامل شخصية المعلم & 7 \\
\hline ५qq & 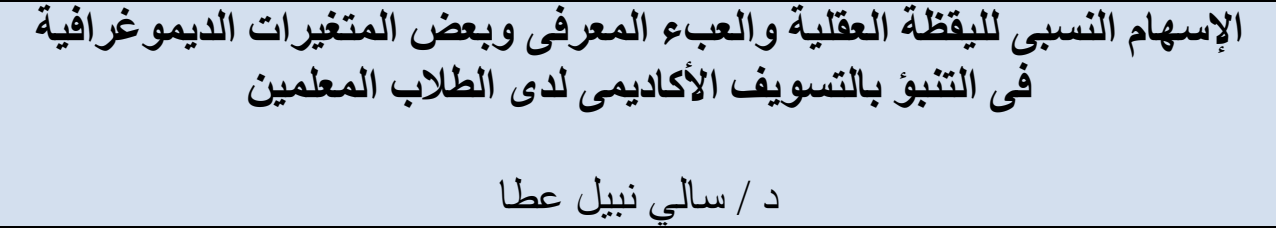 & V \\
\hline$r v r$ & 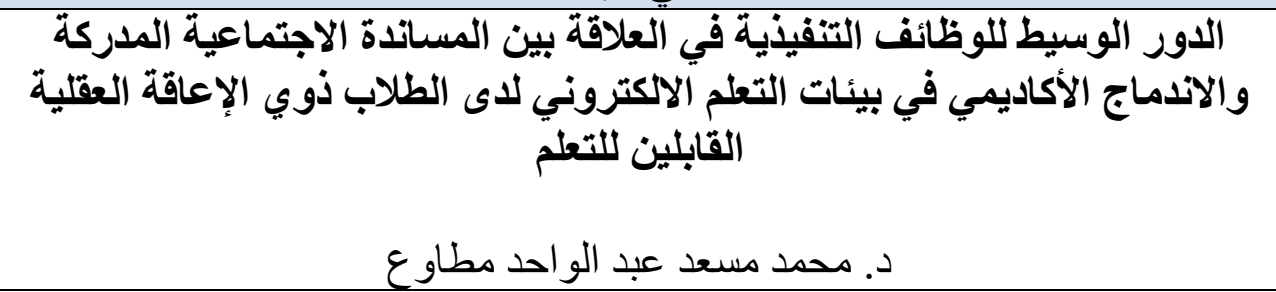 & $\wedge$ \\
\hline
\end{tabular}




\section{فهرس المحتويات}

\begin{tabular}{|c|c|c|}
\hline 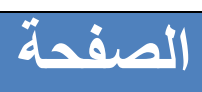 & 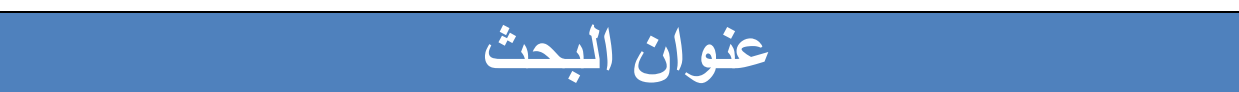 & $\hat{r}$ \\
\hline$\{11$ & 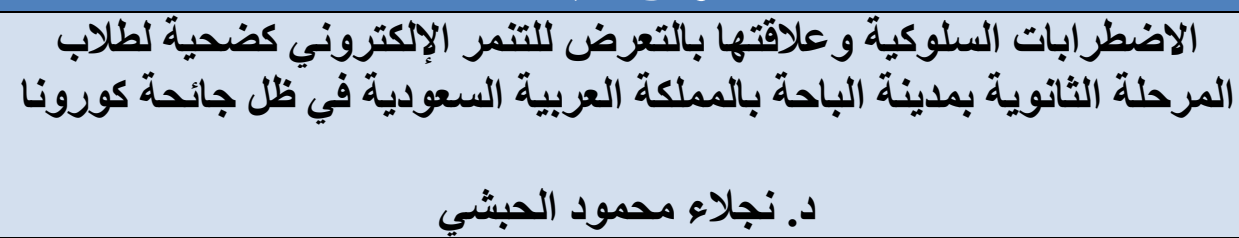 & 9 \\
\hline$\leq \leqslant \leq$ & 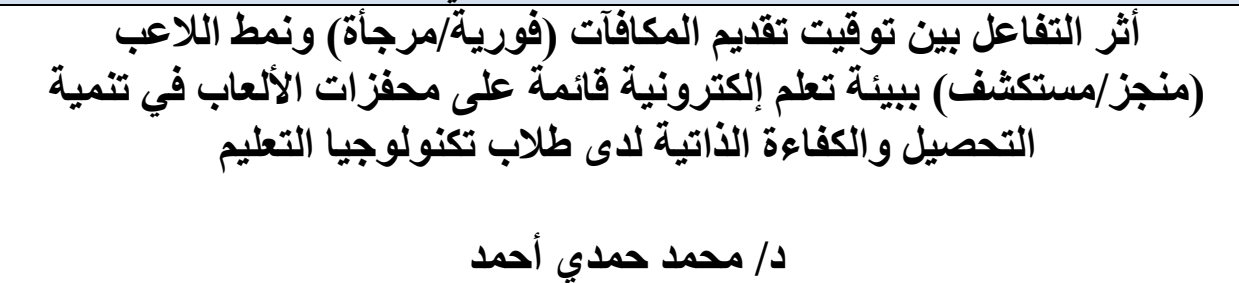 & 1. \\
\hline $01 Y$ & 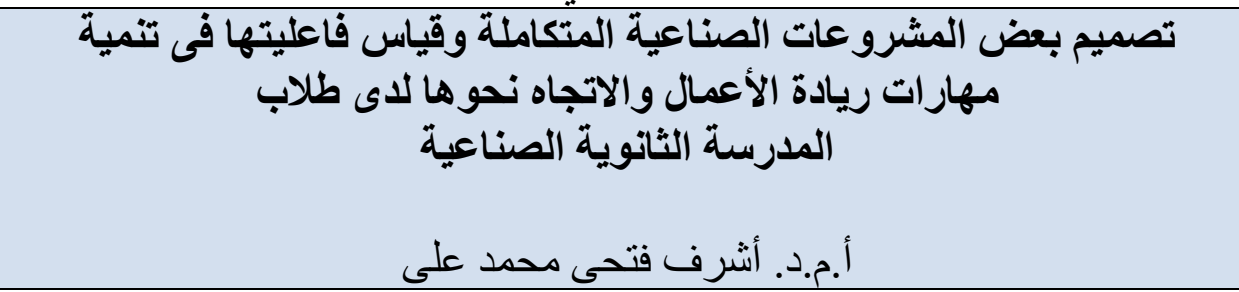 & 11 \\
\hline $0 \wedge 9$ & $\begin{array}{l}\text { Online Debating as a Pedagogy for Enhancing } \\
\text { Argumentative Writing and Reducing Writing } \\
\text { Apprehension among EFL Majors } \\
\text { Dr. Hanan Gamal Mohamed Ebedy }\end{array}$ & $1 \mathrm{~T}$ \\
\hline $71 \%$ & $\begin{array}{l}\text { Effectiveness of the Big6 Model in Developing Student } \\
\text { Teachers' EFL Multimodal Writing Skills } \\
\text { Dr. Hager Gamal Ahmed Labib al-Tonsi }\end{array}$ & 15 \\
\hline
\end{tabular}

